\title{
Collection Management
}

\section{Preservation and Policies in Hellenic Libraries and Archives: A Nationwide Research}

\section{Zoitsa Gkinni}

To cite this article: Zoitsa Gkinni (2015) Preservation and Policies in Hellenic Libraries and Archives: A Nationwide Research, Collection Management, 40:3, 127-148, DOI: 10.1080/01462679.2015.1043419

To link to this article: http://dx.doi.org/10.1080/01462679.2015.1043419

里 Published online: 16 Jul 2015.

Submit your article to this journal $\asymp$

Џ Article views: 134

Q View related articles $₫$

View Crossmark data ¿ 


\title{
Preservation and Policies in Hellenic Libraries and Archives: A Nationwide Research
}

\author{
ZOITSA GKINNI \\ Directorate of Conservation of Ancient and Modern Monuments, Hellenic Ministry of Culture \\ and Sports, Athens, Greece
}

\begin{abstract}
The growing interest in the preservation of archival and library collections in Greece and the lack of documentation in this field led to a nationwide survey to explore the preservation status in Hellenic (Greek) cultural institutions, including public, municipal, academic, and bank libraries as well as the General State Archives. This article describes the survey's background and methodology, presents key findings on the preservation management and actions undertaken, provides a sound documentation on the state of the art regarding preservation, and sets future goals.
\end{abstract}

KEYWORDS Hellenic, libraries, archives, preservation, policy, national survey, Greece

\section{INTRODUCTION}

During the last few decades, there has been a major growth in libraries and archives in Greece. In the 1980s, Hellenic libraries had significant operational difficulties but the funding coming from government grants and benefactors paved the way for their development during the 1990s (Kyrillidou 2005). Recently, libraries and archives have significantly increased actions related to the preservation of their material. Moreover, the growth of digital collections has attracted attention to the maintenance of library and archival collections, both analog and digital. But, despite the discovery of problems related to the preservation of digital objects, the management of preservation needs concerning the analog collections has not drawn the same level of anticipated attention.

(C) Zoitsa Gkinni

Address correspondence to Dr. Zoitsa Gkinni, Directorate of Conservation of Ancient and Modern Monuments, Hellenic Ministry of Culture and Sports, Pireos 81, Athens 10553, Greece. E-mail: zoe.gkinni@gmail.com 
Libraries and archives face constantly increasing demands, technological challenges, and difficulties in funding. However, their organizational structure, especially in the case of public libraries and the General State Archives, could support the dissemination and implementation of preservation planning, within the member institutions or even nationally. Also, there are several nongovernmental organizations that regularly organize seminars and conferences and could contribute toward promoting awareness and disseminating knowledge related to preservation. In this context, the evaluation and assessment of the preservation status in libraries and archives is a fundamental step toward examining their current actions and collaborations in order to prepare for future demands and find new ways for further development (Gkinni 2012).

Until recently, there was a lack of surveys and data on the conservation actions and preservation policies for libraries and archives in Greece. In order to explore the status of preservation in Hellenic libraries and archives, a nationwide survey has been conducted that contributes to the field of national surveys on preservation issues. This survey is part of the author's PhD thesis, which was financially supported by the State Scholarship Foundation in Greece.

This article begins by looking at other national surveys and their outcomes in order to pinpoint their significance and to examine commonalities with this survey. Moreover, recent developments in collections preservation in Hellenic institutions provide a background to the survey and a brief but concrete historical context. The survey's scope and methodology and its key findings provide the basis for the final outcomes regarding preservation management and actions of the participating institutions. This national survey, by collecting and processing original data, provides valuable information and insight that can be used as the basis of current action planning and future reference.

\section{UNKNOWN VARIABLES LEAD TO AN UNCERTAIN FUTURE: THE SIGNIFICANCE OF NATIONAL SURVEYS}

Museums, historical societies, libraries, and archives are responsible not only for collecting, interpreting, and exhibiting significant materials that document history but also for their long-term preservation, security, and accessibility (Ogden 1997). The support offered by these institutions is, to a great extent, a matter of choice, knowledge, and critical decisions. Continuing access to the documentary heritage and the information it contains depends upon appropriate evidence-based stewardship and care of collections (Milne 2006). Surveys have been used for preservation purposes, in order to form a baseline that allows institutions to capitalize on their existing means and plan 
for evidence-based future actions. Within this context, the significance of national surveys is undeniable, since the lack of fundamental knowledge in critical areas of concern can lead to an uncertain future. Moreover, these surveys provide a comprehensive and state-of-the-art view on preservation aspects.

Some countries, such as the United States and the United Kingdom, have been consistent in surveying and documenting their preservation actions and needs in order to help their institutions organize the preservation of their collections at an institutional or broader level. It is not within the aims of this article to present all the national surveys conducted by the various organizations. However, a brief literature review on some of the wellknown national and international surveys demonstrates their contribution in raising awareness regarding preservation practices, their effectiveness in the preservation field, and their impact on a national and international level.

Historically, the interest in the preservation of cultural assets held in libraries and archives across Europe as well as in international agencies developed much later than the research and documentation efforts in US. The lesson to be learned from the American experience and the need for a cooperative scheme was obvious at the Vienna Conference on the preservation of library materials in 1986, where the International Federation of Library Associations (IFLA) core program in preservation was launched (Wilson 1988).

The Association of Research Libraries (ARL) in the US is particularly active in carrying out surveys and presenting statistics from the member libraries. The "Preservation Statistics Survey Program," coordinated by ARL from 1984 to 2008, collected and analyzed a wide range of data on the preservation actions of the library members. In 2009, Meyer (2009) presented a report that summarizes the range of preservation activities pursued by ARL member libraries and provides recommendations about how these libraries should characterize and measure those activities. A discontinuity in the program left the preservation community unable to document and assess the practices implemented, recourses, and strategic direction, but a new survey was conducted in 2013 (Peterson, Robertson, and Szydlowski 2013). This survey was intended for cultural institutions, and as a result, in addition to libraries, several archives and museums participated. The results were presented in the report "A survey of Preservation Activities in Cultural Heritage Institutions: FY2012," which also includes a comparison of statistics among 2007 and 2012 (Peterson et al. 2013).

In 2002, a research report aimed to set up a methodology for assessing non-ARL libraries and establish benchmark data for subsequent longitudinal comparisons. The report focused on key concerns in preserving collections and preservation strategies, as identified by library staff members, which would not be reflected in statistical surveys. Originally, statistical information and other quantitative data relevant to preservation activity were collected and compared with information that had been published in ARL Preservation 
Statistics for 2000-2001, and afterwards qualitative data was obtained in order to complement the statistical data (Kenney and Stam 2002).

In the field of archives, the National Association of Government Archives and Administrators (NAGARA) conducted a study in 1986 in order to determine the extent of preservation problems among the state archives in the United States. The results indicated a preservation problem of massive proportion as well as the fact that these archives cannot find the necessary internal resources to comply with the mandate of preserving their archival records. Moreover, the state archives were understaffed with no extra personnel to work on preservation programs, and existing staff was not sufficiently trained to carry out preservation activities (Lowell 1986). ${ }^{1}$

More recently, the Heritage Preservation, in partnership with the Institute of Museum and Library Services, presented the "Heritage Health Index," the first comprehensive survey on the condition and preservation needs of all US collections held in public trust (Heritage Preservation 2005). The sample group included archives, libraries, historical societies, museums, archeological repositories, and scientific research collections. According to the findings, the majority of institutions do not have employees dedicated to collection care, whereas millions of objects are in urgent need of treatment. Moreover, preservation lacks stable funding and the majority of institutions have no emergency plan.

At a European level, the initiative in national surveys on preservation came from the UK, France (Desgraves 1982), and West Germany (Fabian 1983, Kaltwasser 1986), ${ }^{2}$ and later on, other countries followed, for example, the survey carried out between 1992 and 1997 on the state of collections and preservation conditions of repositories in Estonia (Konsa 2007). In addition, there were two research projects carried out, in 1988 and 1996, for European institutions. More specifically, Alexander Wilson (1988) presented a study on the policy and practice on conservation and preservation in the libraries of the (then) European Economic Community (EEC) countries, by reviewing the preservation scene on an international basis and then surveying the preservation needs and provision on a country-by-country basis. Visits were paid to institutions in Belgium, France, Italy, the UK, West Germany, the US, and Canada (Wilson 1988). The study is more extensive in its coverage of preservation practices in the countries visited. The findings showed that there were common trends observed in the major EEC countries and although awareness was growing rapidly it was not transmitted into decisive action. No country had a national policy and structure for preservation and preservation resources were grossly inadequate (Wilson 1988).

About a decade later, Feather and Hopkins (1997) conducted a survey on the preservation policies in European Research libraries. ${ }^{3}$ This survey showed that preservation policies were limited in number and were very diverse. Foot (1999, 324) comments that: "This diversity is of course not surprising. Preservation policies are written for a number of different reasons and are 
governed by a variety of local circumstances. In some cases the policies are written in order to establish priorities and thus to formulate preservation programs; in some cases they form an argument for funding, being part of the regular cycle of budgeting and bidding."

In the UK, there is a number of surveys that presented the state of the art at each period, starting with the "Ratcliffe Report." This survey was conducted as part of the Cambridge University Library Conservation Project (Ratcliffe and Patterson 1984) and had a significant contribution to the examination of the preservation status in UK libraries. ${ }^{4}$ The findings showed that "few libraries had preservation policies and of those only the largest can afford to pursue them in any realistic sense. Moreover, there was no national plan or even the making of one (...), preservation was not included in library school curricula and the opportunities for the binders and conservators are plainly inadequate" (Ratcliffe and Patterson 1984, iv). In the report's conclusions, among others, the lack of prioritizing preservation measures is stretched, since priorities operate on an ad hoc basis.

In 1993, following the Ratcliffe Report, the research project "Preservation Policies and Conservation in British Libraries: a Ten-Year Review" presented detailed information about the state of preservation management in British libraries (Feather, Matthews, and Eden 1996). ${ }^{5}$ Compared to the Ratcliffe Report's findings, there was an increase in the number of libraries that had developed formal preservation policies; however, the number was still low ( 51 out of 488). Libraries had to work within the narrow constrains of human and financial resources and it was apparent that many librarians saw the future of their libraries in terms of instantaneous access to information rather than the long-term preservation of the collections.

Another project, presented in 1996, provided an overview of current and recent (from 1984) research in preservation management appropriate to British Libraries and Archives (Matthews 1996). It offered thorough documentation of the various research topics relating to preservation and the related projects and also identified research gaps. Although the emphasis is placed on the UK, research projects from Australia, Europe, and the US are also mentioned.

In order to fill the research gap on the preservation status of British archives, Feather and Eden (1997) were engaged in new research that aimed to analyze the existing preservation policies and practices in UK archives and also to obtain data comparable with that already collected for libraries. In the long term, it hoped to produce guidelines for archives wishing to develop their own written preservation policies and to suggest a framework for the development and implementation of a national preservation strategy for libraries and archives in UK (Feather and Eden 1997). Among other results, the findings showed that preservation management plays a central role in the everyday work of archives, but only a minority of the questionnaire respondents had a written preservation policy (Feather and Eden 1997). 
Each of the aforementioned research projects provided important findings that depicted the landscape of preservation in British institutions, supported a national scheme regarding preservation, and of course following the Ratcliffe Report, led to the establishment of the National Preservation Office (NPO) in 1984. In the following years, the former NPO, now called the Preservation Advisory Centre, demonstrated a constant interest in a national preservation scheme. In 2006, it presented the results of the first largescale survey of the state of preservation in the UK's libraries and archives. "Knowing the Need" is a report of preservation surveys carried out using a standard methodology in a large number of libraries and archives throughout UK over a five-year period (2001 to 2005). ${ }^{6}$ This survey focused on surveying the collections rather than on preservation actions and strategies, but among other results, the findings showed that the materials surveyed were well cared for and that good practice in preservation was widespread in both libraries and archives (Walker and Foster 2006). Moreover, in 2013, the Preservation Advisory Centre presented the results of a survey carried out from 2006 to 2011, under the same title. The survey used the same methodology, providing comparable results (Peach and Foster 2013).

At an international level, IFLA and the International Council on Archives (ICA) jointly undertook a survey funded by UNESCO. It was conducted in 1986 and aimed to characterize the international situation with respect to conservation and preservation, to identify the priority problems, to outline the basis of an action program that needed to be undertaken, and to formulate recommendations directed to UNESCO, IFLA, ICA, and national institutions and associations. It concluded that "the results of the questionnaire, the information provided in the mission reports, and the additional information provided by a few selected countries clearly demonstrates the huge scale of the preservation and conservation problem that is faced in protecting library and archival materials which represent an important component of the world's cultural heritage" (Clements 1987, 20).

About ten years later, in 1996, the results of a second survey conducted by the IFLA on behalf of UNESCO were published, as part of the "Memory of The World" program. The survey was prepared by Jan Lyall and its purpose was to identify the level and amount of preservation action and training in major libraries throughout the world and to obtain specific information regarding the holdings of significant documentary heritage. ${ }^{7}$ The findings generally showed that preservation of nationally significant documentary heritage does not have a high priority for many libraries throughout the world and the percentages of the preservation policies and the specialized staff to care for library materials are very low (Lyall 1996.). ${ }^{8}$

The aforementioned surveys responded to the various research gaps between different time periods (1986 and 1996) and institutions. However, 
they share a lot of similarities in their methodology and in their finding $s$. They all identified deficiencies in preservation management and actions, pinpointed the institutions' limitations on resources and gaps in education and training, and tried to diagnose how preservation is conceived and supported by professionals. As it appears, the majority of national surveys presented here focus on one target group, either libraries or archives. In some cases, the research methodology aimed to serve as a benchmark for those that will follow for a specific target group concerned, which is important for longterm conclusions. Moreover, one survey (Lowell 1986) related to the creation of a tool that can be used by archives in order to help them manage the preservation of their collections.

In this context, the survey described in this article aims to fill the gap in exploring preservation issues in Hellenic libraries and archives by providing a wide range of data as a baseline for further actions. The demand for a nationwide survey regarding preservation issues had been raised occasionally since the early 1990s; Peltikoglou $(1993,32)$ noticed that "the condition of the library and archival material has not been documented nationwide." The absence of this sort of a nationwide survey that documents matters such as preservation needs based on the collections' condition, or preservation's organization according to the range and the type of preservation activities currently being implemented by cultural institutions, has been a major drawback for organizing preservation nationally. Similar to the situation in other countries, such a survey can play a crucial role as a starting point for the advancement and management of preservation activities carried out by the abovementioned institutions. Currently, libraries and archives in Greece do not follow a national preservation policy for their collections. Although this occurs in most European countries, it is still a drawback toward efficient and effective management of their collections. Moreover, there is no national organization competent enough to assume the preservation and conservation of libraries' and archives' collections, although organizations such as the National Library and the Central Service of the General State Archives could provide a role model and a competence center.

\section{THE NATIONAL SURVEY ON THE PRESERVATION STATUS OF THE HELLENIC LIBRARIES AND ARCHIVES}

The national survey presented here primarily aims to clarify the institutions' current preservation actions, policies, and overall approach toward preservation. The survey investigated current infrastructure, facilities, and skills available that in turn enabled the realization of conservation and preservation activities necessary to define and adopt a national preservation policy. 


\section{Scope and Methodology}

As already mentioned, the survey is part of a PhD thesis. In the beginning, the scope and aims of the research were clearly defined and limitations on time, budget, and resources were acknowledged.

The survey was conducted in order to map the current situation regarding the organization and implementation of preservation in Hellenic institutions. Moreover, it aimed to answer questions related to the implementation of preservation actions, the context in which these actions are undertaken, and the potential development of preservation as a key factor in the operation of libraries and archives. Thus, the influence of the organizational structure of institutions in the implementation of preservation actions and the ongoing support conservation actions were tested at the institutional and national levels.

In particular, the survey examined whether (1) the available human resources, funding, and equipment ensured collections maintenance; (2) there were preservation policies implemented that supported actions related to the care and preservation of collections and identified the factors that supported such policies; (3) institutions cared for the long-term preservation of their collections and to what extent they implemented preservation actions; (4) the preservation actions were supported by appropriate building infrastructure and equipment; (5) training in preservation influenced the implementation of preservation actions and to what extent; and (6) there were state organizations or structures that could play a central role in organizing and promoting the preservation of the collections in the near future and what their structure, scope, and offer could be.

After thorough bibliographic research, the survey tools were determined and the sample (the institutions' profile and number) was confirmed. The survey included two phases, a pilot questionnaire, and the main survey. The pilot questionnaire aimed to explore the level of preservation activities in libraries and archives. It was distributed to a small number of professionals employed in libraries and archives in November 2006 and about ten months later the data collected was analyzed. These primary data informed the formulation of a working hypothesis and were taken into account when designing the main survey, which included a second questionnaire and interviews with selected institutions. Data from both the second questionnaire and the interviews were analyzed.

The main questionnaire extends to five pages and comprises mainly of closed-ended questions (yes/no) and also includes dichotomous, nominalpolytomous, ordinal-polytomous, and open-ended questions. Questions aim to collect data on the institutions' profile, type, size, and significance of their collections, issues regarding preservation policies and prioritization, conservation and preventive conservation actions, training of the employees, digitization, and disaster management. The questions were divided into six 
thematic categories covering a number of key issues, as presented in Table 1. Moreover, the questionnaire also included an introductory part, which included a cover letter, instructions on how to answer the questions, and a short glossary of the main terms: preventive conservation, remedial conservation, preservation, preservation policy, preservation program, preservation survey, and assessment.

Between February and April 2008, questionnaire 2 was posted and emailed to the identified sample of institutions. Wherever necessary, a second round of questionnaires was dispatched in order to increase the response rate. The data collected were then coded and analyzed using SPSS, a widespread software package for statistical analysis.

\section{Survey Sample and Response}

The survey aimed to collect data from a wide range of institutions such as libraries and archives. The target population size included 346 institutions, divided into five groups: general state archives, public libraries, municipal libraries, academic libraries, and bank libraries. All libraries apart from the last group are state-owned. Overall, 153 institutions replied (44.5\%), but the response rate varied among the five groups. The response was high for public libraries and for general state archives and modest for the rest of the groups (see Table 2). It should be noted that the National Library did not participate in the survey (both in the questionnaire and the interviews) despite several telephone contacts and after having been sent the questionnaire.

\section{Survey Findings and Analysis}

The survey provided a wide range of results regarding the preservation actions currently being taken, as well as the institutions' capabilities profile, since it examined the existing means, such as available human resources, budget, and equipment, but also perceived outcomes and preconditions for a better performance. It tried to identify explanatory patterns, to interpret the results, and thus to describe emergent trends. Initial findings are presented according to the above-mentioned categories.

\section{Institutions' Organization AND PRESERVATION}

The vast majority of the sample institutions is financially supported by the Hellenic State. Municipal libraries ("demotikes") are managed and financed by local authorities, whereas public libraries ("demosies") are managed and supported by the Ministry of Education. The same ministry also supports academic libraries, through universities and technological institutions, and 
TABLE 1 Thematic Categories and Key Issues Covered in Questionnaire 2

\begin{tabular}{|c|c|}
\hline Thematic Categories & Key Issues \\
\hline $\begin{array}{l}\text { Institution's organization } \\
\text { model and preservation }\end{array}$ & $\begin{array}{l}\text { - Human resources: number, qualifications, specialization } \\
\text { (paper conservators, preservation officer) } \\
\text { - Human resources vs. institutional needs } \\
\text { - Preservation actions and type (preventive/remedial } \\
\text { conservation) } \\
\text { - Conservation lab } \\
\text { - Annual preservation budget } \\
\text { - Cooperation with private conservators or other institutions } \\
\text { for conservation needs }\end{array}$ \\
\hline
\end{tabular}

Collections status

- Type of materials (books, archives, photographs, audiovisual, etc.) and their frequency within collections

- Collections' date and significance in local and national level

Policies and priorities for preservation

- Preservation policy: written or within future plans, significance, advantages, staff involvement and participation, parameters for conducting a preservation policy

- Conservation programs

- Survey and assessment of collections' condition

- Frequency of damages versus type of materials

- Digitization projects and their sustainability

- National preservation policy and benefits for institutions

Preventive conservation

- Environmental conditions in storage areas

- Environmental control and equipment

- Handling of materials

- Cleaning storage areas and collections

- Disinfection of storage areas

Human resource training

- Training of employees in preservation issues

- Assessment and support of training according to collections' and institution's needs

- Type of training (seminars, conferences, short courses by educational institutions or the NCPAG)

Disaster management

- Disaster incidents

- Security systems

- Fire detection/control and available equipment/system

- Disaster planning and response

- Drills and tests 
TABLE 2 Sample Institutions and Their Response Rates

\begin{tabular}{lccc}
\hline Institutions & $\begin{array}{c}\text { Population Size } \\
\text { (Sample) }\end{array}$ & Respondents & Response Percentage \\
\hline General state archives & 62 & 46 & $74.2 \%$ \\
Public libraries & 47 & 34 & $72.3 \%$ \\
Municipal libraries & 189 & 52 & $27.5 \%$ \\
Academic libraries & 37 & 17 & $45.9 \%$ \\
Financial institution & 9 & 4 & $44.4 \%$ \\
$\quad$ libraries & 344 & 153 & $44.5 \%$ \\
Total & & & \\
\hline
\end{tabular}

the general state archives. The national authority in charge of all public archives, the "Eforia" of the General State Archives, is the decisive body in matters of archival policy (Calimera Project, n.d.). The financial institution libraries are the only exception since they are predominantly supported by the private sector.

The findings revealed that despite the shortage of adequate resources (human, equipment, and budget), according to current needs, institutions tend to perform conservation actions, both preventive and remedial; care for their collections; and maintain an overall positive attitude toward preservation. In particular, the majority of institutions are understaffed, since $80.7 \%$ employs only up to seven persons, although academic and financial institution libraries usually have more employees than the rest of the groups. Moreover, most institutions (84\%) support that existing human resources cannot address their current needs. Institutions were categorized according to their number of employees into three groups: small (up to seven employees), medium (eight to eighteen employees) and large (more than nineteen employees). ${ }^{9}$ Two institutions, the central service of the General State Archives in Athens and the library and information center of the University of Macedonia in Thessaloniki, presented the highest number of employees (forty-five). The differentiations on institutions' size among the five institutions' categories are presented in Figure 1.

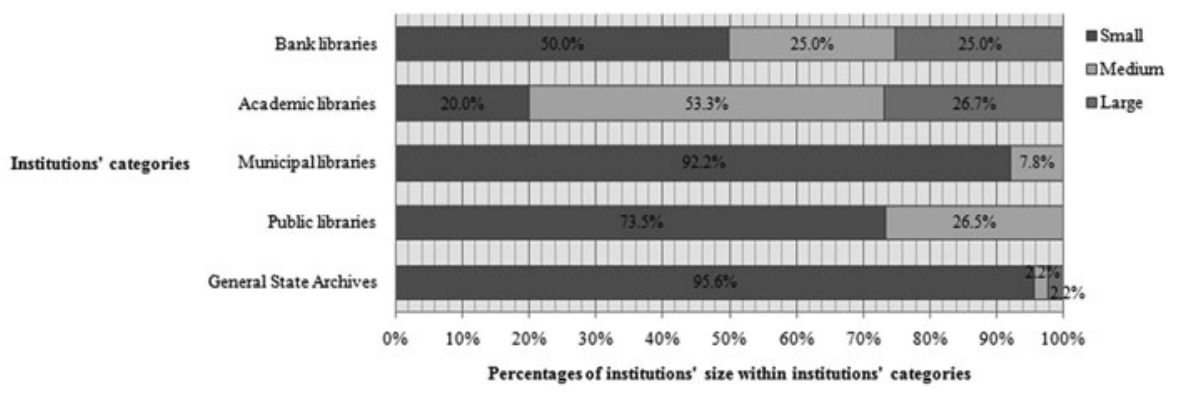

FIGURE 1 Institutions' size allocation by institution's categories. 


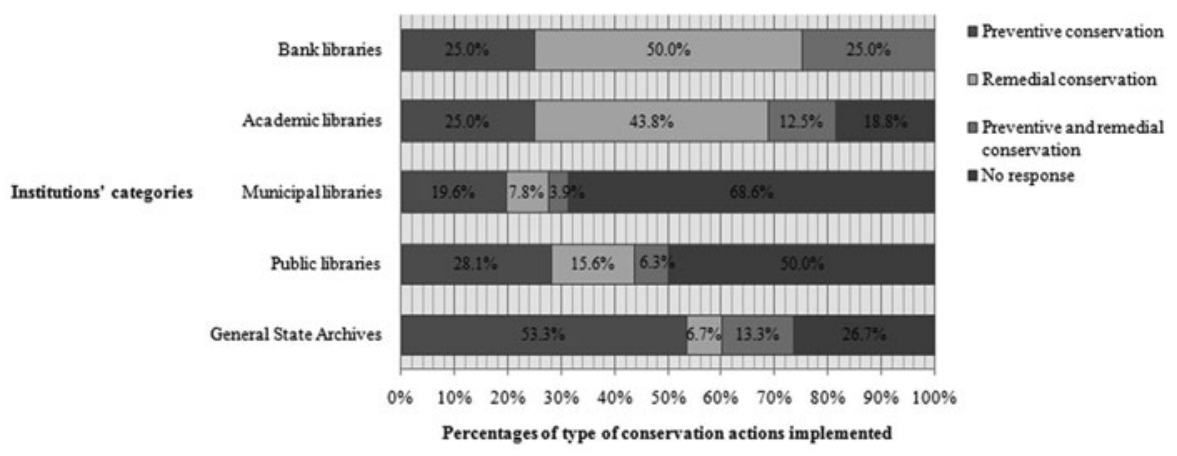

FIGURE 2 Type of conservation actions implemented allocation by institutions' category.

Institutions support preservation activities, since more than half (55.9\%) undertake conservation treatments $(32.2 \%$ preventive conservation, $14.1 \%$ remedial conservation, and $8.7 \%$ both). The type of conservation actions implemented by institutions' categories is presented in Figure 2. To a large extent, institutions that have claimed to implement remedial conservation do not display the necessary preconditions, such as specialized conservators, organized conservation labs, or external cooperations, resulting in certain actions being perhaps performed by nonspecialized staff. The data showed that $92.1 \%$ do not employ paper conservators, but $50.7 \%$ claim to have a preservation officer, who may be an archivist/librarian/conservator (23.8\%) or other $(25.2 \%)$.

Data analysis revealed that the institution's size influences the implementation of preservation actions only in the case of large institutions, whereas in small and medium-sized institutions a difference in the impact is not clearly evident. It does, however, influence the type of preservation actions (preventive and/or remedial) undertaken, since large institutions support both preventive and remedial actions, whereas medium-sized institutions support remedial actions and small institutions only support preventive actions. Furthermore, large institutions tend to cooperate with external institutions (private or public) for preservation purposes, rather than employ specialized conservators; furthermore, it seems that most cooperative actions for preservation are a response to the institutions' needs rather than as a strategic choice.

\section{COLLeCTiOnS}

A range of data relating to the identity of the institutions' collections (type, date, significance according to their own opinion) was collected. The findings on the type of collections showed that $98.7 \%$ of the institutions keep book collections, $81.7 \%$ archival collections, $67.1 \%$ audiovisual collections, and 


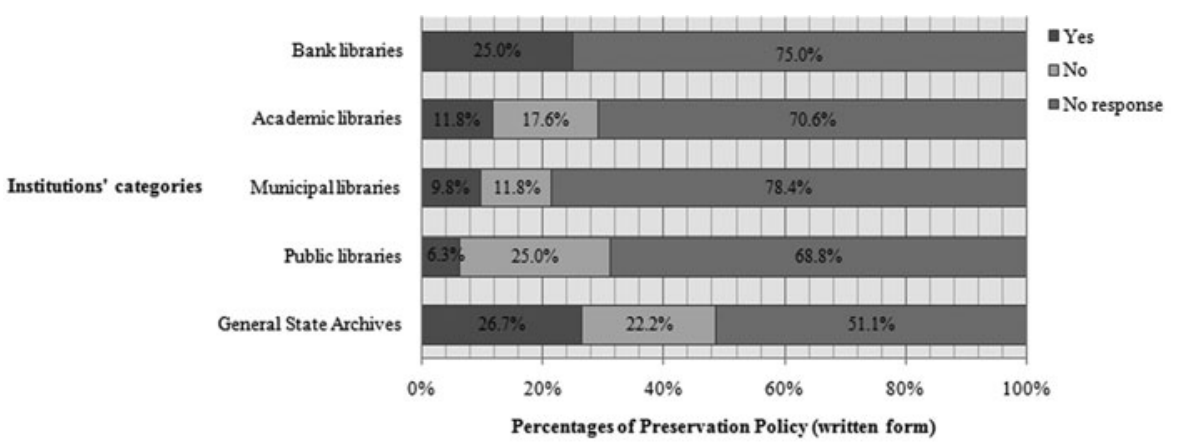

FIGURE 3 Preservation policy (written form) allocation by institutions' category.

42.1\% photographs. A smaller percentage (19\%) also possess works of art, museum objects, charts, etc. Moreover, the majority of the institutions (61.8\%) have both historic and modern collections.

The analysis showed that the collection's date did not influence the management and implementation of preservation actions, although it was originally considered as a factor of significance. For example, it does not influence variables such as the employment of conservators and a preservation officer or the undertaking of preservation actions. In fact, institutions with historical collections focus more on preventive conservation, whereas those with modern collections prefer remedial conservation. This is probably explained by the fact that these institutions tend to systematically keep the collections in a usable condition. Historic collections, on the other hand, demand a considerable investment in time, human resources, and a budget for conservation actions.

\section{Policies AND Priorities For Preservation}

The vast majority of institutions are aware of the benefits of a preservation policy, with $91.7 \%$ supporting that a preservation policy could help them in their goals and objectives. However, only $25.8 \%$ of all institutions stated that they have had a preservation policy of some form in place, but there are variations among the groups, whereas only 14.8\% declared that they had their preservation policy in a written form. The percentages of institutions' having preservation policies in a written form varied among the five categories, as shown in Figure 3.

Finally, 53.5\% declared that they planned to formulate a preservation policy in the near future. However, it is important to note that there is a confused perception of what a preservation policy is, what it could achieve, how it could contribute to the collection's maintenance, and how it is involved in the organization's daily operation. Preservation policies are usually perceived as an obligation to exercise central policy, rather than an institutional 
necessity for such an initiative. However, more often than not, preservation policies are not in line with expected actions, such as collections condition assessment and coexistence with policies on the collections' development and withdrawal. On the other hand, institutions that claimed to have formulated a preservation policy undertake preservation actions at a higher percentage than the rest (66.7\% compared to 51.4\%) and tend to collaborate more for preservation purposes $(33.3 \%$ compared to $16.4 \%)$. Preservation policies are not statistically associated with the employment of conservators, but they are favored in institutions that have concrete acquisition and retention policies. Moreover, they influence collaborations for collections conservation, disaster planning, and digitization actions. So, it is obvious that these policies, in any form, have clear benefits.

On a national level, the need for an overall approach toward collections preservation for libraries and archives emerged from both the survey and the interviews. It is widely acknowledged that a national or regional policy could serve collections preservation in the best possible way. In fact, 98.6\% of the institutions support that forming a national preservation policy, with specific preservation actions and programs, would assist them in their work. Moreover, a regional or national approach toward a preservation policy could help institutions manage their preservation needs efficiently, providing them with necessary knowledge and support, especially to small and medium-size institutions with limited resources.

Interviews recorded a range of opinions on the way that a national preservation policy could be supported in order to be effective. A regional strategic plan that would potentially lead to a policy could be manageable if it is supported by a group of institutions. The interviewees supported the idea of cooperatives with a manageable number of institutions with common interests and were in favor of reorganizing and amplifying the existing central institutions with the potential of playing a central role in preservation.

\section{Preventive Conservation}

The institutions' preventive conservation actions regarding storage and handling were further examined. The results showed that almost half of the institutions (49.3\%) control the environmental conditions within the storage areas. Among the environmental parameters, $41.2 \%$ of the institutions control temperature, 30.4\% relative humidity, and 38.5\% lighting and only $6.1 \%$ control air pollutants. The equipment most frequently used are air conditioning, heating, and dehumidifiers, combined with good housekeeping actions. Moreover, $76.4 \%$ report regular cleaning of their storage areas, $69.1 \%$ perform regular cleaning of their collections, and $46.7 \%$ disinfects their storage areas regularly, although the materials or equipment used were not defined. Despite regular cleaning and controlling environmental conditions in storage areas, institutions reported having collections damaged by insects (50.3\%), 


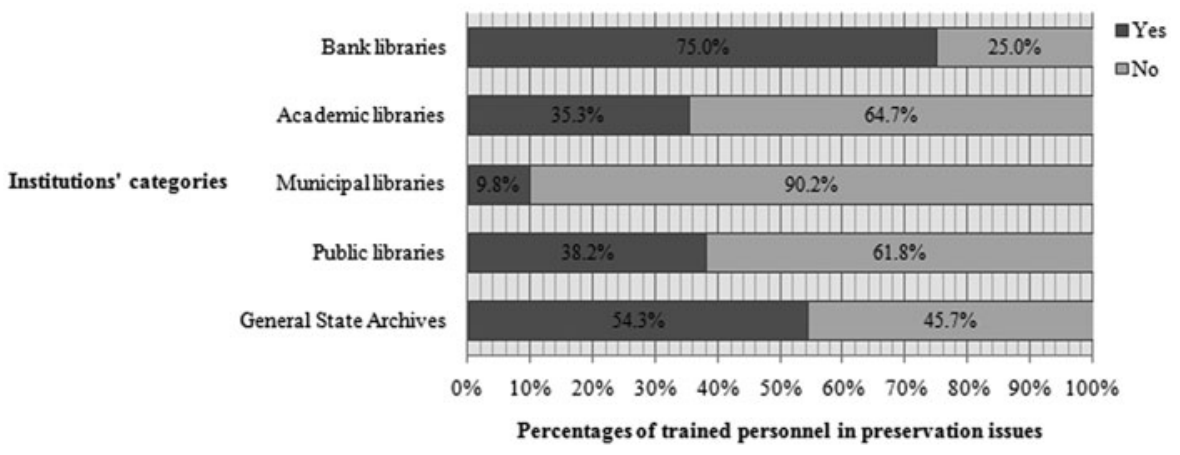

FIGURE 4 Trained personnel allocation by institutions' category.

rodents (27.2\%), and mold (53.6\%). These findings showed that in several cases, preventive measures already taken are not adequate for long-term storage.

In the case of collection handling, $80.4 \%$ of the institutions have an employee responsible for guiding and supervising visitors on how to properly handle collections. Since many institutions are engaged in digitization projects, the number of institutions with available digitized collections is growing fast. Currently, $48.3 \%$ of the institutions provide visitors with the original copy, whereas the rest has substitutes, such as photocopies and digitized materials. Safe handling and substitutes contribute to collections preservation, and it seems that institutions are well aware of their benefits. Generally, preventive actions are preferred by institutions with conservators and preservation policies, but in institutions where there are no conservators employed, higher rates of preventive actions, such as environmental control and handling guidance, are attributed to personnel trained in preservation.

\section{Human Resources Training}

Institutions with personnel that have been trained in preservation issues are a minority (34.2\%), but a significant variance is displayed among the groups, as shown in Figure 4.

However, training personnel on preservation issues is highly appraised, since $88.7 \%$ of the institutions support that it is important because it helps meet their needs. Also, several institutions replied that trained personnel can partially cope with the lack of specialized conservators and resources, and 91.8\% encourages training and claims that lifelong professional education plays an important part in its development. Explanatory comments that elaborated on the advantages of training in preservation included enhanc- 
ing the institution's services, updating its knowledge of the developments in conservation, covering existing needs due to lack of qualified personnel, and implementing efficiently preventive conservation actions. As aforementioned, personnel trained in preservation influences the implementation of preventive conservation actions. Moreover, it influences cooperation in preservation with other institutions and the implementation of preservation policies.

Training is offered through the institutions, as workplace training programs (14\%), university training programs or equivalent courses (12\%), and conferences/seminars (18\%), but the majority (35.3\%) reported that their personnel was trained by the official training organization for public-sector employees. ${ }^{10}$ This organization has played an important role in raising preservation awareness by offering weekly seminars on preservation issues, such as preventive conservation actions; collections' handling, storage, and environmental control; preservation policies; and more.

\section{Disaster MANAGEMENT}

There are important weaknesses in disaster management, since the findings showed that there are deficiencies in safety measures and a lack of organization for disaster preparedness. Only 29.9\% of institutions have a disaster plan and only $9.5 \%$ perform regular preparedness exercises. These low percentages in disaster planning and preparedness are probably due to ignorance, negligence, or lack of expertise. Moreover, low rates (21.1\%) of recorded cases of disasters, such as flood, fire, or earthquake, have also contributed in this direction. The findings showed that $56.2 \%$ of the institutions take measures for the prevention and response in case of disasters. However, $58.2 \%$ declared having a security system, $47.4 \%$ a fire detection system, and $66.4 \%$ a fire suppression system. As expected, the analysis showed that the institution staff plays an important role in disaster preparedness, since preservation officers influence disaster planning and trained personnel influence the measures for prevention and response.

\section{THE SURVEY'S CONTRIBUTION: LOOKING INTO THE FUTURE}

Based on the findings, preservation policies and the employment of trained personnel in preservation are two parameters that should be given special emphasis at an institutional and/or cooperative basis. Caring for all collections cannot be based solely on specialized staff who are rarely employed, but on all employees who should be trained and informed about preservation issues and who are capable of supporting basic preservation actions and participating in decision making for collection maintenance. There- 
fore, trained employees are crucial for raising awareness and promoting preservation as an essential institutional action at an equal level with all the others.

At an institutional level, weaknesses in planning and implementing preservation actions are due to the organization of their operation and the lack of resources and expertise. These factors influence institutions in the way they prioritize collections management. Nationally, the weaknesses recognized were mostly due to the lack of "best practices" as guidelines and the support of staff trained in preservation. Moreover, there are no robust organizational planning and corresponding structures that will enable the sustainability of preservation actions. Until now, there has been no central organization to support and promote the preservation of the libraries and archives collections. And finally, there is a lack of institutionalization of the various preservation and conservation actions (as standard practices) and a lack of a dissemination scheme for the necessary expertise in institutions.

Institutions declared it necessary to further support preservation through training, best practices, and resources. Interviews provided a series of proposals regarding the essential organizational changes and the characteristics that a coordinative action or a national preservation plan entail. In brief, this national approach should be in the context of a partnership between institutions and a central organization, such as the Central Service of the General State Archives or the National Library, which, on a national level, will support long-term training and the dissemination of knowledge through seminars/publications/workshops, but will also provide guidance through best practices and/or standards. This national scheme could also be supported by the various professional or scientific associations in the preservation field.

So far, shortcomings, such as limited resources and a lack of expertise in preservation, have led to an inquiry and a demand for standards that emerge from best practice examples, such as organizing conservation and disaster management and recovery. The survey showed that a key step toward effectively supporting conservation actions would be to enhance the capabilities and reach of a central body, such as the National Library and the Central Service of General State Archives in Athens, as the main response to the widespread need for horizontal assistance and guidance in matters of conservation in small institutions. There is also plenty of room for the growth and organization of conservation actions in central institutions, which could provide help to small institutions.

Besides proposing a scenario for national planning in preservation, this research has contributed toward raising the awareness of and implementing preservation policies on multiple levels, through interviews, the dissemination of the results, as well as the development of a new self-assessment tool called the preservation policy maturity model. The data and conclusions of this research enabled the design and development of this tool, which focuses on the libraries' and archives' performance regarding preservation, 
rather than their collections' preservation status. It is a practical preservation policy maturity model, aimed at assisting Hellenic libraries and archives in formulating a preservation policy, by answering simple questions that assess preservation performance against peer best practice, thus self-assessing their maturity level (Gkinni 2014).

\section{CONCLUSION}

In an era of fast change and volatility, cultural institutions need to adapt. Libraries and archives have to reexamine their role and goals regarding the preservation of their collections and undergo a phase of real change in order to keep up with the new demands that they are being faced with. Although there has been a noticeable development in libraries and archives across Greece over the past few decades, there are still deficiencies and gaps relating to preservation issues. The survey presented in this article, for the first time on a national scale, mapped the problems that institutions face with regard to managing their collections and presented in detail the current situation with regard to their preservation status. Furthermore, through interviews and the dissemination of its results, the survey also raised the institutions' awareness of preservation issues and policies.

The survey's findings pinpoint concrete evidence of preservation practice issues and developments revealing the preservation status in Greek libraries and archives as well as areas in need of improvement. Institutions have better access to skilled staff and training programs relating to preservation than in the past, and this has led to a growing interest and knowledge of preservation (Gkinni, Bounia, and Pavlogeorgatos 2008). Their cultural property is indeed cared for and they are generally aware of the role of preservation in collection management. However, in practice, preservation is less important than other services, for example, than acquisitions or access to digital collections. Although progress has been made, there are still inherent weaknesses that should be addressed. These weaknesses include available resources as well as the managerial aspect of their exploitation. Institutions undertake a range of preventive conservation actions, but they continue to show problems in organizing preservation and supporting specialized and sophisticated treatments. Libraries and archives need to focus more on managing the preservation of their collections and implementing preservation policies. Such policies are currently more necessary than ever, since resources are limited and a coherent framework and clear navigation pathway can safeguard collection maintenance and continuous improvement.

There is clear evidence that, on a national scale, collaborative activities for preservation are more effective in General State Archives than in libraries. Such actions and initiatives should be further supported. A national preser- 
vation policy remains a constant objective, but regional preservation policies could be effective and easier to implement. An important step forward in this direction would be to further support and promote surveys and tools that organize and assess preservation status and institutional needs. Further assessment can lead to the design a roadmap of interventions, initially on an institutional scale, which has to be evaluated in terms of its progress. This roadmap could provide a single and shared basis of coordinated actions with milestones that, through an institutional network for the collaboration, allow for the exchange of experiences and good practices and could collectively achieve the realization of the objectives and standards of an emerging national preservation policy for libraries and archives.

Furthermore, the challenge is to manage the preservation of analog material in conjunction with digitized and born-digital material, resulting in a holistic approach to the conservation of cultural assets. A plausible scenario could be to equally support regional or national preservation practices for both analog and digital materials, since both types of collections have to be treated with the same respect for their value, under a principle of an egalitarian approach to cultural heritage.

\section{ACKNOWLEDGMENTS}

I would like to thank the institutions and individuals that participated in the survey and Professors Gerasimos Pavlogeorgatos and Alexandra Bounia for their support and supervision.

\section{FUNDING}

I would like to thank the State Scholarship Foundation in Greece for financially supporting the research carried out during my Ph.D. thesis.

\section{NOTES}

1. This study was used as a basis for the tool NAGARA-GRASP that aimed to help archivists design a comprehensive plan for the conservation of their institutions cooperatively with other archives as part of the team (Curtin 1990).

2. These two surveys did not focus on preservation but included it as part of a broader research.

3. The survey initially used questionnaires and, as a second step, the libraries that were identified to have preservation policies were then approached and asked to send a copy of their policy.

4. The survey methodology included a preliminary survey that acted as a preparatory work, with visits to various institutions, a pilot, and a main questionnaire.

5. This questionnaire-based survey focused on the preservation management practices in British libraries and the data were analyzed using Minitab statistical software.

6. This methodology serves as potentially constant feedback from institutions on a national level, since a standard method, preservation assessment survey (PAS), was used as tool for obtaining a reliable 
snapshot picture of the state of preservation of a library/archive collection. Librarians, archivists, and conservators, with the guidance from the NPO staff, carried out the preservation surveys using PAS (Walker and Foster 2006).

7. The aim was to create a working tool using UNESCO software products CDS/ISIS and IDAMS Analysis of the data collected was facilitated by the use of IDAMS, a statistical package developed for use with CDS/ISIS (Lyall 1996).

8. The questions and the sample of the 1986 IFLA/ICA and UNESCO survey and the current (1996) survey were similar but not the same, so direct comparisons were difficult to be made. Furthermore, it appeared that the UNESCO publication of guidelines for the development of preservation and conservation policies for libraries and archives (see Chapman 1990) did not result in an increase in conservation policies (Lyall 1996, 3.2).

9. This categorization is a result of statistical analysis using K-means cluster analysis. (EKDDA)

10. Training Institute of the National Centre for Public Administration and Local Government

\section{REFERENCES}

Calimera Project. Country Report: Greece Information on Public Libraries, Local Museums and Archives. ICT Programme-Cultural Applications: Local Institutions Mediating Electronic Resources (CALIMERA), European Commission. Available at: http://www.infolibraries.gr/wp-content/uploads/2009/04/FD86821Fd01.pdf

Chapman, Patricia. 1990. Guidelines on Preservation and Conservation Policies in Libraries and Archives. Paris: UNESCO. Available at: http://unesdoc.unesco. org/images/0008/000863/086345Eo.pdf

Clements, David, W. G. 1987. Preservation and Conservation of Library and Archival Documents: A UNESCO/IFLA/ICA Enquiry Into the Current State of the World's Patrimony. General Information Programme and UNISIST. Paris: UNESCO.

Curtin, Bonnie Rose. 1990. "Preservation Planning in Archives Paper," The Book and Paper Group Annual 9 (1990). Available at: http://cool.conservationus.org/coolaic/sg/bpg/annual/v09/bp09-05.html.

Desgraves, Louis. 1982. Le Patrimoine des Bibliotheques. Paris: Minister de la Culture.

Fabian, Bernhard. 1983. Buch, Bibliotheck und Geisteswissenschaftliche Forschung. Gottigen: Vandenhoeck und Ruprecht.

Feather, John, and Paul Eden. 1997. "National Preservation Policy: Policies and Practices in Archives and Record Offices," British Library Research and Innovation Report 47. London: British Library Research and Innovation Center.

Feather, John, and Tracy Hopkins. 1997. Survey of Preservation Policies in European Research Libraries. Leicestershire, UK: Loughborough University.

Feather, John, Graham Matthews, and Paul Eden. 1996. Preservation Management, Policies and Practices in British Libraries. Aldershot: Gower Publishing Limited.

Foot, Mirjam M. 1999. "Towards a Preservation Policy for European Research Libraries," LIBER Quarterly 9 (3): 323-326. Available at: http://liber.library. uu.nl/publish/articles/000326/\%20article.pdf

Gkinni, Zoitsa. 2012. "National Collaboration for Preservation Policies: Prospects and Key Issues." Presentation at the 21st Panhellenic Conference of Academic Libraries: The Face of Libraries is Continually Changing: Synergy and Development Strategies with Inspiration and Vision, Piraeus, Athens, October 18-19, 2012. 
Gkinni, Zoitsa. 2014. "A Preservation Policy Maturity Model: A Practical Tool for Greek Libraries and Archives." Journal of the Institute of Conservation 37 (1): 55-64.

Gkinni, Zoitsa, Alexandra Bounia, and Gerasimos Pavlogeorgatos. 2008. "The Contribution of Digitisation to the Preservation of Books and Archives: The Case of the General State Archives and the Public Libraries in Greece." In Proceedings of Digital Heritage in the New Knowledge Environment: Shared Spaces \& Open Paths to Cultural Content, 162-165. Athens: Ministry of Culture, Directorate of the National Archive of Monuments.

Heritage Preservation. 2005. A Public Trust at Risk: The Heritage Health Index Report on the State of America's Collections. Washington: Heritage Preservation \& the Institute of Museum and Library Services. Available at: http://www.heritagepreservation.org/hhi/HHIsummary.pdf.

Kaltwasser, Franz Georg. 1986. "Probleme der Literaturversorgung in den Geisteswissenschaften," ZIBB 33 (2): 92-99.

Kenney, Anne, and Deirdre Stam. 2002. The State Preservation Programs in American College and Research Libraries: Building a Common Understanding and Action Agenda. Washington, DC: Council on Library and Information Resources.

Konsa, Kurmo. 2007. "Condition Survey for the Estonian National Preservation Policy." Restaurator 28 (4): 239-255. Munich: Saur.

Kyrillidou, Martha. 2005. "Library Assessment: Why Today and Not Tomorrow?" In The Library Assessment Conference, 2005. Thessaloniki: Council of the Technological Educational Institution of Thessaloniki. Available at: http://www.libqual.org/documents/admin/KyrillidouGreecePapers.doc.

Lowell, Howard P. 1986. Preservation Needs in State Archives. Albany: National Association of Government Archives and Records Administrations.

Lyall, Jan. 1996. "Memory of the World": A Survey of Current Library Preservation Activities. Paris: UNESCO.

Matthews, Graham. 1996. Research in Preservation Management. British Library Research and Innovation Report 30. London: British Library Research and Innovation Center.

Meyer, Lars. 2009. Safeguarding Collections at the Dawn of the 21st Century: Describing Roles \& Measuring Contemporary Preservation Activities in ARL Libraries. Washington, DC: Association of Research Libraries.

Milne, Ronald. 2006. Foreword to Knowing the Need: A Report on the Emerging Picture of Preservation Need in Libraries and Archives in the UK, edited by Mary Feeney. London: National Preservation Office.

Ogden, Sherelyn. 1997. Preservation Planning: Guidelines for Writing a Long-Range Plan. Andover: American Association of Museums, Northeast Document Conservation Center.

Peach, Caroline, and Julia Foster. 2013. Knowing the Need. Optimizing Preservation for Library and Archive Collections. London: Preservation Advisory Centre.

Peltikoglou, Vassilios. 1993. "Permanent Paper: Attempts to Confront the Damages of Library and Archival Materials and Secure the Prolongation of Their Life Cycle," Archival News 8: 32-33. Available at: http://www.eae.org.gr/ Texts/pub_an_08b.pdf.

Peterson, Annie, Holly Robertson, and Nick Szydlowski. 2013. A Survey of Preservation Activities in Cultural Heritage Institutions: FY2012 Report. 
Chicago: Association of Research Libraries (ARL) and Association of Library Collections and Technical Services (ALCTS). https://docs.google.com/ document/d/1k4TKSO34kodsQuOE-CFxgAfUWgeCt1cK7rofDd92yOs/edit.

Ratcliffe, Frederick William, and D. Patterson. 1984. "Preservation Policies and Conservation in British Libraries: Report of the Cambridge University Library Conservation Project," Library and Information Research Report 25. London: The British Library.

Walker, Alison, and Julia Foster. 2006. Knowing the Need: A Report on the Emerging Picture of Preservation Need in Libraries and Archives in the UK. London: National Preservation Office.

Wilson, Alexander. 1988. Library Policy for Preservation and Conservation in the European Community: Principles, Practices and the Contribution of New Information Technologies. Commission of the European Communities. Munchen, New York, London, Paris: K G Saur. 